\title{
Farmacologia: 0 aprendizado de forma lúdica
}

\author{
Karla Meira Castro Zepponi ${ }^{1}$, Luzmarina Aparecida \\ Doretto Braccialli ${ }^{2}$, Osni Lazaro Pinheiro ${ }^{3}$ \\ 1Docente da Escola Técnica Estadual (ETEC), Mestrado em Educação em \\ Saúde na FAMEMA, São Paulo, Brasil | ka.zpp@hotmail.com | \\ https// orcid.org/0000-0001-8052-3626 \\ ${ }^{2}$ Docente na Faculdade de Medicina de Marilia/Brasil; Doutorado em Ciências na \\ EEUSP/Brasil | luzbra@terra.com.br | https//orcid.org/00002-9622-8629 \\ ${ }^{3}$ Docente na Faculdade de Medicina de Marilia/Brasil; Doutorado em Ginecologia, \\ Obstetrícia e Mastologia na UNESP/Brasil | osnilp@terra.com.br | https// orcid.org/0000- \\ 0002-6533-0428
}

Resumo: Introdução: Na formação profissional o uso de jogo educacional associado a situações da prática de farmacologia proporcionaram ao estudante uma forma concreta e lúdica de aprendizagem. Objetivo: Analisar o uso de um jogo educacional de forma lúdica com aplicação de conceitos básicos de farmacologia. Método: Estudo qualitativo, com abordagem observacional e descritiva. A coleta de dados foi realizada com juízes com experiências em ensino e em farmacologia. Os juízes validaram o jogo por meio de um questionário que continha um campo aberto o qual realizaram suas considerações e sugestões de melhorias. Foi elencado os núcleos de sentido e uma análise de conteúdo na modalidade temática. Resultados: As temáticas foram: Facilidades de aprender conceitos básicos de farmacologia por meio de um jogo e Dificuldades encontradas para aprender conceitos básicos de farmacologia, ambas foram trabalhadas para buscar melhoria no jogo e seus conteúdos. Considerações finais: Os jogos foram validados pelos juízes que apontaram sugestões relevantes para aprimorar o material didático, o conteúdo, as regras do jogo e possibilitar uma aprendizagem compátivel ao ensino técnico de farmácia.

Palavras-chave: Aprendizagem; Ensino; Jogo; Farmacologia; Material Didático.

\section{Pharmacology Content: Learning in a Playful Way}

Abstract: Introduction In professional training, the use of an educational game associated with situations of pharmacology practice provided the student with a concrete and playful form of learning. Objective: To analyze the use of an educational game in a playful way with the application of basic pharmacology concepts. Method: Qualitative study, with an observational and descriptive approach. Data collection was carried out with judges with experience in teaching and in pharmacology. The judges validated the game by means of a questionnaire that contained an open field which made their considerations and suggestions for improvements. The nuclei of meaning and a content analysis in the thematic modality were listed. Results: The themes were: Facilities to learn basic pharmacology concepts through a game and Difficulties encountered to learn basic pharmacology concepts, both were worked to seek improvement in the game and its contents. Final considerations: The games were validated by the judges who pointed out relevant suggestions to improve the didactic material, the content, the rules of the game and to enable a compatible learning to the technical teaching of pharmacy.

Keywords: Learning; Teaching; Game; Pharmacology; Teaching Materials.

\section{Introdução}

A modalidade de Educação Profissional de Nível Técnico aproxima o estudante do mercado de trabalho. Há uma série de desafios para possibilitar um Ensino de qualidade vinculado a área profissional, romper a referência do Ensino tradicional e trazer ensino com competência nos cuidados humanos. A inovação em estratégias de aprendizagem envolvidas na formação do curso técnico é oportunizar o protagonismo do estudante em sua formação profissional (Marine,2013, Bertuzzi, 2006).

Os elementos lúdicos para ensino e aprendizagem podem ser fatores indispensáveis para possibilitar a participação ativa do estudante.

Proporcionam o desenvolvimento das competências na esfera formativa, seja em comunicações, relações entre os estudantes, cooperação e competição e desta forma favorece o conhecimento (Gonzaga, et al. 2017; Ministério da Educação, 2006). 
A orientação dos Parâmetros Curriculares Nacionais (PCN) é que os conteúdos sejam associados e contextualizados com as situações cotidianas para fomentar o senso crítico e desta forma permitir a aprendizagem na construção do conhecimento por meio de estímulos a aplicação do conhecimento (Silva \& Bianco, 2020; Ministério da Educação, 2006).

Segundo a $\mathrm{PCN}$, os jogos educativos proporcionam prazer, permite a absorção de conteúdo, traz a espontaneidade, o estímulo e a criatividade (Gonzaga, et.al. 2017; Ministério da Educação, 2006). Além de possibilitar a competitividade, interação entre os estudantes e a disciplina. É importante definir regras, limites e tempo, a forma de apresentação das atividades e seus objetivos, tudo isso proporcionando satisfações e tensões na busca por vencer, gerando desafios e despertando impulsos, cooperação e colaboração (Brunton, Hital-Dandan \& Knollmann, 2018). Todo esse processo depende do propósito do jogo e das regras elaboradas, sendo importante contemplar conteúdos que busquem o raciocínio e a construção do conhecimento.

Com as premissas do uso de jogos educativos em sala de aula foi desenvolvido o jogo: "Roleta do Conhecimento", com o propósito de subsidiar conhecimento por meio de conteúdos com conceitos básicos em farmacologia e regras para ser aplicado aos estudantes do Ensino Técnico de Farmácia (Zepponi, Braccialli \& Pinheiro, 2020).

Para tanto, tem-se como questão norteadora do estudo: $O$ jogo educacional aplicado de forma lúdica pode proporcionar aprendizagem de conceitos básicos de farmacologia em estudantes de nível técnico do curso de farmácia?

Frente a este contexto estudo teve como objetivo: Analisar o uso de um jogo educacional de forma lúdica com aplicação de conceitos básicos de farmacologia.

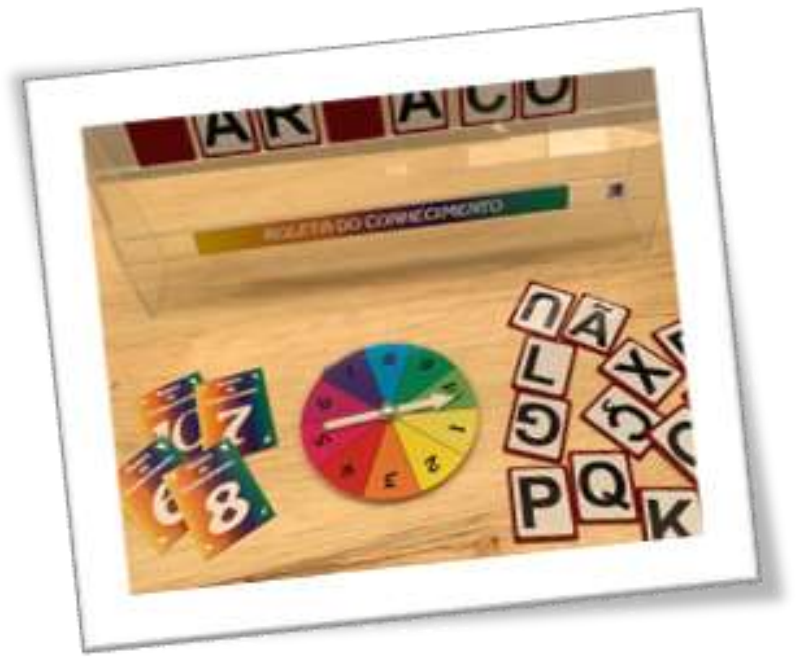

Fig. 1. Jogo educacional para aplicação no curso técnico de farmacologia, elaborado pelos autores.

\section{Metodologia}

O estudo é descritivo e observacional com coleta de dados de maneira prospectiva. Esse teve aprovação do Comitê de Ética em Pesquisa Envolvendo Seres Humanos de um Instituição Pública do Estado de São Paulo, Brasil (CAAE 03948318.4.00005413). O trabalho foi desenvolvido pelos autores do estudo, envolveu a análise de um jogo educacional "Roleta do Conhecimento" de forma lúdica com aplicação de conceitos básicos de farmacologia.

O jogo "Roleta do Conhecimento" foi elaborado, estruturado e construído com sua base e peças em acrílico, sendo a base transparente, as peças na cor vermelha e as letras pretas impressas em plástico adesivo branco que foram adesivadas nas peças vermelhas. 
O jogo foi desenvolvido em acrílico transparente com desenho da roleta colorido afixado sobre ela, a qual foi colocado uma seta de acrílico branca, afixada com um parafuso.

As regras do jogo consistiam em dez pistas que levavam a identificação da palavra secreta, estas eram numeradas por cartas, que ao girarem a roleta, abririam a pista correspondente ao número. Os participantes iam se alternando e dizendo as letras correspondentes as palavras, ao término do jogo era contemplado o estudante que acertava a palavra referente ao conteúdo proposto de farmacologia.

Os conceitos básicos que foram utilizados para este jogo estão na ementa do Curso Técnico em Farmácia: Farmacocinética (absorção, distribuição, metabolismo e excreção), Interações medicamentosas (fisicoquímica, farmacocinética e farmacodinâmica) e vias de administração. Foram selecionados aleatoriamente por sorteio quatro juízes da área de Farmacologia sob os critérios de experiência docente em farmacologia em curso superior, formação superior em farmácia, experiência docente em curso técnico; para à área de Ensino foram selecionados quatro participantes com experiências profissionais com métodos ativos e confecção e aplicação de jogos no ensino superior. Suas identificações foram preservadas com códigos alfanuméricos ( 11 a J8).

Os juízes da área de Farmacologia receberam dois questionários com conteúdo/objetivo e relevância dos jogos com conteúdo voltado para a disciplina de Farmacologia. Os juízes da área da Educação receberam dois questionários, porém, ligados à estrutura/organização e ludicidade, portanto, envolvendo regras, aplicabilidades e apresentação dos jogos (Simões, Silva, Alves \& Silva, 2016, Ministério da Educação, 2013).

As primeiras avaliações realizadas pelos juízes foram em salas com os jogos dispostos sobre a mesa, acompanhado de manuais, conteúdos, cartão de pontos e o instrumento avaliativo. Os juízes individualmente analisaram os jogos de acordo com os itens relacionados a cada área (farmacologia/ensino) e preencheram os instrumentos avaliativos. Os jogos que não atingiram os níveis de concordância mínimo (70\% segundo estudo quantitativo realizado anteriormente pelos autores) foram readequados de acordo com os apontamentos dos juízes e submetidos a uma segunda avaliação. Nessa avaliação os juízes receberam as alterações e conteúdos via email, juntamente com o instrumento avaliativo com os mesmos critérios de avaliação. Após ser validado, o jogo foi aplicado aos estudantes do Curso Técnico de Farmácia sobre os conteúdos básicos de Farmacologia. Os conteúdos abordados foram previamente trabalhados com os estudantes em sala de aula.Os dados qualitativos foram extraídos dos depoimentos dos juízes nos campos abertos, identificando os núcleos de sentido.

O material empírico foi trabalhado na modalidade temática, que é preconizada por buscar características que são relatadas com frequência no conteúdo avaliado. As falas foram analisadas com o intuito de obter padrões que se assemelhavam nos conteúdos das falas. (Bardin, 2012; Minayo, Deslandes, \& Gomes, 2016). O material foi lido, interpretado, analisado para buscar uma compreensão das palavras e suas relações, os quais identificou-se os núcleos de sentido. (Minayo, Deslandes, \& Gomes, 2016) Desta forma foi permitido interpretar os depoimentos dos juízes, buscando as vivências, um diálogo e uma melhor interpretação (Minayo, 2012).

As interpretações e vivências dos juízes trouxeram contribuições relevantes para o estudo, considerando suas experiências com o processo de ensino e aprendizagem. A compreensão traz a singularidade das situações que é advindo da junção destes fatores e visão individual, mesmo com discordância perante uma situação que foi analisada por várias pessoas (Minayo, 2012).

Buscou-se as informações neste estudo, minimizar contaminações e interpretações equivocadas e atentar-se aos detalhes. Desta forma, a definição das duas temáticas seguiu à ordenação realizada por avaliações e a classificação dos aspectos positivos e negativos relacionados ao uso do jogo educacional de forma lúdica e à aprendizagem dos conceitos básicos de farmacologia pelos estudantes do curso técnico de farmácia. (Minayo, 2014, Moreira, et al. 2019). Não foi desprezado detalhes e comentários que expressavam significados, nem o contexto empírico e o sentido das falas, deste modo, 
houve uma análise compreensiva, baseadas em teorias, com o propósito de trazer um material fiel e coerente. (Minayo, 2012).

\section{Resultados e Discussão}

Com a leitura exaustiva dos campos abertos dos instrumentos foi possível identificar os seguintes núcleos de sentidos relacionados a facilidades e dificuldades com o aprendizado de farmacologia de forma lúdica. Os núcleos de sentido que compreenderam as facilidades foram: a fixação de conteúdo, a diversão, a autoavaliação, a simplicidade, a coesão nas respostas, a aplicação em sala de aula, o desenvolvimento de raciocínio, a integração entre os estudantes, a agilidade do jogo, a escolha dos conceitos, o planejamento dos conteúdos e a pertinência do jogo. Os núcleos de sentido que compreenderam as dificuldades foram: aprendizado difícil dos conceitos básicos de farmacologia, regras não claras no jogo, limitação e necessidade de adequação do número de estudantes, a competitividade, utilizar da sorte no jogo, dificuldade de discutir comportamento e aprendizagem no jogo, disciplina quanto ao cumprimento das regras, o tempo de aplicação, conceitos não relevantes que foram selecionados, raciocínio por meio de interpretação.

Esses núcleos de sentido foram agrupados e trabalhados nas temáticas: Facilidades de aprender conceitos básicos de farmacologia por meio de um jogo e Dificuldades encontradas para aprender conceitos básicos de farmacologia por meio de um jogo, apresentadas a seguir.

\subsection{Facilidades de Aprender Conceitos Básicos de Farmacologia por Meio de um Jogo}

O movimento de trabalhar o conhecimento de farmacologia por meio de aprendizagem lúdica, buscando pistas para chegar aos conceitos básicos em farmacologia, permite uma melhor compreensão do conteúdo de forma simples, coesa e usa o raciocínio, além de contar com a colaboração dos colegas de equipe. Os juízes apontam que a intencionalidade do jogo como ferramenta de aprendizagem, com linguagem adequada e cuidados na elaboração de regras, objetivo, tema do conteúdo e desenvolvimento do raciocínio, pode beneficiar a aprendizagem:

O jogo aborda os conceitos fundamentais na área citada. Em cada área os tópicos abordados tem que ser bem escolhidos para a máxima compreensão. Há a necessidade de um bom planejamento para que o conteúdo seja completamente ministrado (J5).

Gostaria de pontuar que tudo vai depender das pistas. Desperta o raciocínio caso as pistas sejam boas ( $\mathrm{J} 6$ ).

Muito bom para a fixação do conteúdo, bom o apresentado anteriormente. Divertido, fornece uma autoavaliação bem como a avaliação do professor (J3).

Jogo propicia raciocínio, integração entre os alunos e uma auto avaliação, o que considero importante despertar nos alunos (J3).

A diversão, a facilidade de fixação do conteúdo por meio de recursos lúdicos de forma divertida, facilita a aprendizagem e apropria conhecimentos devido a interação e a possibilidade de proatividade do estudante (Silva \& Bianco, 2020).

Pires et al., (2015) reforçam à aprendizagem articulada ao lúdico, a rotina de estudos, aos sentimentos e as reflexões proporcionadas entre os estudantes que participam do jogo.

O jogo deve ser bem pensado e elaborado de maneira simples, ser atrativo sem dificuldades de entendimento na dinâmica proposta para facilitar a aprendizagem (Silva \& Bianco, 2020). Neste jogo, o docente consegue fazer ajustes nas abordagens das pistas. Traz a possibilidade de diversificar conteúdos, com maior ou menor aprofundamento no tema que está sendo estudado (Darroz, 2018). 
A simplicidade, a coesão, à facilidade de aplicação apontadas pelos juízes reafirma a possibilidade de utilizar este jogo de forma tranquila, proporcionando melhora no racíocinio, no aprendizado e no desempenho do educando, além da socialização, comunicação e interação entre os estudantes. O jogo "Roleta do conhecimento" tem uma aplicabilidade bem simples, sendo importante para o entendimento dos estudantes. A abrangência dos temas abordados na farmacologia permite a elaboração de muitos conceitos relacionados a essa área básica do conhecimento que pode facilitar a compreensão. A Farmacologia tem temas muito complexos e este jogo materializa o aprendizado desses estudados durante o ano letivo. As pistas devolvem o raciocínio, permitindo ao estudante fazer conexões antes de responder.

A simplicidade e coesão desta proposta são sensacionais. É de fácil aplicação em sala de aula. Gostei muito (J1).

Existe a intenção de simplificar e promover a criatividade. Desta forma procura-se encontrar o equilíbrio entre educação, aprendizagem e diversão (Almeida, Amaral, Pieri \& Matar, 2017).

\subsection{Dificuldades Encontradas para Aprender Conceitos Básicos de Farmacologia por Meio de um Jogo}

Existem alguns elementos importantes para a construção de jogos lúdicos, ligado a imaginação que pode simular algo da vida real; as regras objetivas e fáceis de entender; a mistura de sensações, voltadas para tensões e diversões; o propósito de chegar ao objetivo do jogo; a disciplina, que preconiza seguir regras e direcionamento para concluir o jogo (Filho \& Schröter, 2018).

Os juízes enfatizaram a importância da manutenção ou aperfeiçoamento das regras e seu grau de dificuldade para os estudantes. Esta pode ser uma dificuldade encontrada e deve ser bem pensada.

Não está claro o preparo do jogo. Quem escolhe a palavra secreta, o professor? O auxiliar? Palavra secreta como Farmacologia por exemplo pode ser bem fácil dos jogadores acertarem e isso pode ir desestimulando-o (J2).

Quanto às regras, poderia já deixar claro que os números da roleta correspondem ao número da pista, não colocar em dois itens porque um fala dos adversários e outro do auxiliar, são dois sujeitos diferentes, mas a roleta define a regra para o jogador (J4).

Os dois participantes só poderão adivinhar ou dizer a palavra no final? Porque se a palavra tiver número par de letras um dos jogadores se beneficiará e, se for ímpar o outro (J4).

Sempre adequar as pistas com grau de dificuldade compatível com a turma as questões não podem ser fáceis e o difícil deve ser possível (J4).

Construir o conhecimento, por meio de métodos ativos, com o auxílio, poderá colaborar para o despertar da prática da educação em saúde e desenvolver no estudante 0 as habilidades e atitudes por meio da reflexão e criticidade que o método proporciona (Limberger, 2013).

Schröter, 2018 em suas pesquisas, destaca as necessidades de associar o lúdico com a simulação da vida real, a objetividade e a organização de regras claras, ênfase em diferentes sensações como tensão, mistério e desafio. Para chegar ao objetivo proposto do jogo e a disciplina para o cumprimento das regras. Estes aspectos vão ao encontro dos comentários dos juízes, citados acima. Priorizando a melhoria do jogo, todos as recomendações dos juízes foram acatadas. Outro aspecto apontado foi a limitação de estudantes para a aplicação do jogo.

Limitação é atender a três alunos apenas a não ser que a palavra secreta tenha um número reduzido de letras, visto que o jogo tem 49 cartas (J2). 
Pensando na melhoria, houve readequação de regras, para possibilitar maior cooperação e formação de equipes. Esses aspectos realmente favorecem o jogo, a competitividade traz relações de cooperação (Faeti \& Calsa, 2015).

A tendência a competitividade, a promoção da disciplina e a sorte, são pontos relevantes que podem trazer uma melhor dinâmica ao jogo. Esses aspectos foram vistos entre as dificuldades conforme falas abaixo:

Analise da ludicidade: vou fazer as considerações das questões que discordei: Os jogos individuais tendem a ser competitivos, nunca colaborativos. Mas quando um jogo tem entre as regras algum grau de "sorte" a competição vai diminuindo em relação a demonstração do conhecimento. Se cada aluno coloca uma letra e não pode dizer a resposta, aquele que ficar por último poderá se beneficiar ainda que não saiba muito, pois nesse tipo de jogo as vogais são as primeiras apresentadas e tendem a ser mais de uma de cada, algumas consoantes são mais frequentes na área, como a letra $F$ (fármacos, farmácia, etc.) além de outras (J4).

Dificuldade no jogo de discutir comportamento/ aprendizagem (J4).

Disciplina referente ao cumprimento das regras e respeito aos participantes (J4).

Comportamento e aprendizagem não podem ser discutidos, nesse jogo, como disciplina. Se houver indisciplina o professor saberá que o jogo está desinteressante apenas isso (J4).

Acredita-se que a ludicidade fornecida pelo jogo, pode favorecer a compreensão do conteúdo e ser mais atrativa por trazer a coletividade, cumprimento de regras e até mesmo a ética por promover a disciplina. Foi pensado sob a ótica de uma estratégia que estimule o raciocínio possibilitando erros, deduções e acertos além de trabalhar as frustrações (Kikot, Fernandez \& Costa, 2015). A disciplina referida é por trabalhar o respeito às regras, as equipes e não referentes aos estudantes ficarem estáticos. Com tudo, espera-se a harmonia dos estudantes na aplicação do jogo.

Como todo jogo, o estudante também contará com a sorte de algumas pistas serem mais direcionadas e também de que o adversário erre. Acredita-se que isso deva ser um impedimento para o aprendizado, visto que se aborda em sala de aula a importância da participação e dos diferentes meios de aprendizagem. $O$ universo lúdico prepara o estudante para a sociedade com regras coletivas e estabelece limites entre o lúdico e a vida real (Faeti \& Calsa, 2015).

A questão seguinte traz dificuldades do trabalho em equipe.

Jogos individuais não incentivam trabalho em equipe. Entendendo trabalho em equipe como uma ação que requer todos se engajem para atingir um objetivo comum. (J4)

No cenário atual, com a evolução dos estudantes pela busca da aprendizagem, ainda que com regras, traz o aspecto da cooperação, do comprometimento e promove a integração, desta forma, pode-se perceber a naturalidade salutar deste processo. Mesmo que haja competição, o respeito e a ética prevalecem entre os estudantes e as equipes. E para melhorar a dinâmica do jogo, os estudantes foram separados em equipes.

Desta forma, a competitividade trará diferenças entre significados e resignificado pelos papéis dos estudantes no jogo e assim proporcionar um ambiente de competição, que acaba por estabelecer cooperação (Faeti \& Calsa, 2015).

Outro aspecto relevante, foram as considerações voltadas para questões de memorização e readequação do conteúdo para melhorar o raciocínio e irrelevância do conteúdo por ser conceitual, e parecer não importantes para a formação. Conforme citado a seguir, foram prontamente melhorados.

Novamente penso que nos itens das fichas para cada palavra secreta remetem a memorização (J7). 
Mais uma vez, depende das pistas (J6).

As palavras apresentadas remetem a conceitos clássicos e por isso não relevantes na formação $(J 7)$.

Os juízes apontaram a relevância do conteúdo, por buscar a melhoria do jogo, foram feitas revisões, procurando trazer uma linha de raciocínio nas pistas. A intenção é aproximar o estudante de estratégias que estimulem a curiosidade a partir da compreensão do objeto de estudo e não apenas transmitir conhecimentos, que favoreça a memorização (Cristine, 2013). Algumas pistas foram otimizadas ou inteiramente reelaborados, trazendo uma proposta de maior raciocínio. A teoria da aprendizagem diz que o estudante aprende quando o ambiente é significativo e com isso acaba favorecendo sua proatividade (Demo, 2009). Os métodos ativos fomentam uma mudança nesta visão, deixa a fragilidade da memorização e dá espaço para aprendizagem significativa, que faz associação entre a informação e um novo significado trabalhando a cognição preexistente (Darroz, 2018, Carvalho, et al. 2016).

Houve questionamentos a cerca do tempo do jogo, o tempo de aula é de duas horas e cinco minutos, buscando a adequação para melhor execução do jogo, as regras foram alteradas, possibilitando que os estudantes possam trabalhar em equipes. Criar e elaborar as regras otimiza o entendimento do jogo, que é fundamentado em concepções teóricas, que culmina o processo lúdico (Pires, et al, 2015).

O jogo não ocupa muito espaço, ainda que isso precise ser considerado sempre. O tempo é rápido para cada palavra, portanto não convém que seja muito prologando para não ficar enfadonho (J4).

Acho pertinente a aplicação do jogo, contudo a preocupação que tenho é com relação ao tempo gasto para a aplicação do jogo e o tempo necessário para ministrar todo o conteúdo (J5).

A adequação das regras é primordial para se alcançar a ludicidade, a qual é caracterizada pela imaginação e participação dos jogadores. Além disso, traz limites entre espaço e tempo, em conjunto com as regras estabelecidas, as quais estarão agregadas ao entusiasmo e a um misto de prazer e tensão. (Pires, et al., 2015) As dificuldades apontadas foram adequadas e os estudantes poderão responder às pistas, logo que souberem a palavra secreta. Os estudantes apenas não poderão exceder o tempo descrito nas regras do manual, conforme sugestão apresentada.

As alterações sugeridas pelos juízes permitiram uma melhor adequação de conteúdos de farmacologia e as regras do jogo, tornando-os mais concisos e objetivos, minimizando possíveis imprevistos no decorrer da aplicação, para possibilitar o processo de ensino e aprendizagem de forma lúdica.

As questões inseridas nos jogos, proporcionaram pôr em prática o desenvolvimento de raciocínio que foi observado pelas argumentações durante as partidas e pela colaboração dos participantes, confirmadas nos questionários respondidos pelos estudantes.

\section{Considerações Finais}

A elaboração do jogo para o ensino em básico de Farmacologia no Curso técnico em Farmácia, foi adequada conforme avaliação dos juízes, seus apontamentos fortaleceram a elaboração do jogo em conteúdo e ludicidade, promovendo assertividade na aplicação e conseqüentemente uma aprendizagem significativa. $O$ jogo preconiza a conexão de aprendizagem na saúde com a profissão de Técnico em Farmácia, por meio das questões de conceitos, atrativas e direcionadas que agregou conhecimento.

A Farmacologia é uma disciplina complexa e seus conceitos fazem parte da sua compreensão, não é uma disciplina que se possa memorizar é preciso entendê-la e compreender a sua aplicação. Saber estes conceitos facilitará entender situações futuras da prática profissional. Trazer esta contextualização das situações profissionais e estimular o raciocínio por meio de estratégias lúdicas, traz uma conexão ímpar para o estudante e os aproxima da realidade profissional. 
As dificuldades foram enriquecedoras, os apontamentos realizados pelos especialistas das áreas de farmacologia e educação, na condição de juízes, relacionados a disciplina, competição e regras claras, mostraram ser primordial para a evolução do jogo no aspecto lúdico.

Este estudo enfatizou a relevância dos jogos no processo de ensino e aprendizagem, como forma de diversificar os processos educativos, motivando os estudantes a aprenderem e refletirem sua prática estudantil e profissional.

\section{Referências}

Brasil, (2013). Ministério da Educação. Diretrizes curriculares nacionais para educação profissional técnica de nível médio. Brasília (DF)): Ministério da Educação.

Zepponi KMC (2020). Jogos Educativos: um recurso lúdico de aprendizagem da Farmacologia para Ensino Técnico. [dissertação]. Marília (SP): Faculdade de medicina de Marília. 183p.

Almeida F. D., Amaral J. W. R., Pieri M. S., \& Matar J. (2017). O jogo do método: jogos de tabuleiro como suporte ao ensino da disciplina Metodologia Científica. Res Soc Dev. 6(2):148-70.

Assis, M. (2001). Uma nova sensibilidade nas práticas de saúde. [A new sensibility in healthcare practices]. Interface - Comunicação, Saúde, Educação, 5(8):139-140.

Bardin, L. (2012). Análise de conteúdo. São Paulo: Edições 70.

Brunton, L. L., Hilal-Dandan, R., \& Knollmann, B. C., (2018). As bases farmacológicas da terapêutica de Goodman \& Gilman. Porto Alegre.

Carvalho, D. P. S. R. P., Vitor, A. F., Barichello, E., Villar, R. L. A., Pereira, V. E. S., \& Ferreira, M. A. J. (2016). Aplicação do mapa conceitual: resultados com diferentes métodos de ensino-aprendizagem. Aquichan, 16(3):382-91.

Cristine, M. D. (2013). Avaliação da experiência de estudantes de farmácia no componente de farmacologia com a utilização da metodologia de aprendizagem baseada em tarefas. Foco. 4(5):89-109.

Darroz, L. M. (2018). Aprendizagem significativa: a teoria de David Ausubel. Espaço Pedagógico, 25(2):577580.

Demo, P. (2009). Aprendizagem e novas tecnologias. RBDEPENF. 1(1):53-75.

Faeti, P. V., Calsa, G. C. (2015). Jogo, competição e cooperação: articulando saberes. Paper presented at the Educere- XII Congresso Nacional de Educação, Pontifícia Universidade Católica de Curitiba.

Filho, F. L. F., Schröter, B. A. F. (2018). O Uso de Jogos Didáticos no Processo de Ensino e Aprendizagem no Ensino Superior. Anais do VIII Congresso Internacional de Conhecimento e Inovação (ciKi). Guadalajara.

Kikot, T., Fernandes, S., Costa, G. (2015). Potencial da aprendizagem baseada-em-jogos: um caso de estudo na Universidade do Algarve. RISTI. (16):17-29.

Limberger, J. B. (2013). Metodologias ativas de ensino-aprendizagem para educação farmacêutica: um relato de experiência. Interface. 17(47):969-75.

Melo, D. O., Molino, C. G. R. C., Ribeiro, E., \& Romano-Lieber, N. S. (2017). Capacitação e intervenções de técnicos de farmácia na dispensação de medicamentos em Atenção Primária à Saúde. Ciência \& Saúde Coletiva. 22(1):261-268. doi:10.1590/1413-81232017221.16122015

Minayo, M. C. S. (2012). Análise qualitativa: teoria, passos e fidedignidade. Ciência \& Saúde Coletiva. 17(3):623-626.

Minayo, M. C. S. (2014). O desafio do conhecimento: pesquisa qualitativa em saúde. (14a. ed.). São Paulo: Hucitec.

Minayo, M. C. S., Deslandes, S. F., Gomes, R. (2016). Pesquisa social; teoria, método e criatividade (1a. ed.). Petrópolis: Vozes.

Moran, J. M. (2000). Mudar a forma de ensinar e de aprender com tecnologias. Revista Interação - Estudos e Pesquisa em Psicologia. Interações. 5(9):57-72.

Moreira, H. M., Higa, E. F. R., Braccialli, L. A. D., Moraes, M. A. A., Tonhom, S. F. R., \& Pinheiro, O. L. (2019). O desafio da avaliação no internato da medicina. Atas CIAIQ. Investigação Qualitativa em Educação. 1(1):516-525.

Pires, M. R. G. M., Göttmens, L. B. D., Silva, L. V. S., Carvalho, P. A., Melo, G. F., \& Fonseca, R. M. G. S. (2015). Desenvolvimento e validação de instrumento para avaliar a ludicidade de jogos em saúde. Revista da Escola de Enfermagem da USP, 49(6):981-990.

Silva, J. C. S., Bianco, G. (2020). Jogos didáticos: a formação educativa através de uma aprendizagem significativa e um currículo adaptado por projetos. Research, Society and Development.9(9):e820997969-e820997969.

Zepponi, K. M. C., Braccialli, L. A. D., \& Pinheiro, O. L. (2020). Elaboração de jogo educacional na farmacologia: A validação por especialistas. New Trends in Qualitative Research, 2, 476-489. https://doi.org/10.36367/ntqr.2.2020.476-489 